\title{
The Smoking Paradox: Impact of Smoking on Recanalization in the Setting of Intra-Arterial Thrombolysis
}

\author{
Elena Meseguer ${ }^{a, c}$ Julien Labreuche ${ }^{c}$ Jaime Gonzalez-Valcarcel ${ }^{a, c}$ \\ Gaia Sirimarco ${ }^{a, c} \quad$ Céline Guidoux ${ }^{a, c}$ Lucie Cabrejo ${ }^{a, c}$ \\ Philippa C. Lavallee ${ }^{a, c}$ Isabelle F. Klein ${ }^{b, c}$ Pierre Amarenco ${ }^{a, c}$ \\ Mikaël Mazighia, c \\ Departments of a Neurology and Stroke Centre and ${ }^{\mathrm{b}}$ Radiology, Bichat University Hospital, \\ and 'INSERM U-698 and Paris-Diderot University, Paris, France
}

\section{Key Words}

Ischemic stroke $\cdot$ Intra-arterial thrombolysis $\cdot$ Recanalization $\cdot$ Smoking

\section{Abstract}

Background: The smoking paradox refers to a better outcome in smokers eligible for thrombolytic treatment in myocardial infarction or ischemic stroke. Recent findings suggest that current smokers may present higher recanalization rates after intravenous (IV) thrombolysis with recombinant tissue plasminogen activator (rt-PA). We evaluated the impact of smoking in a consecutive series of patients treated with intra-arterial (IA) rt-PA. Methods: We analyzed data collected between April 2007 and December 2012 in our prospective registry. All acute ischemic stroke patients with an arterial occlusion treated by IA rt-PA ( \pm IV, \pm thrombectomy) were included. Arterial status was monitored with conventional angiography during the IA procedure. The primary study outcome was a complete recanalization achieved immediately after termination of IA rt-PA infusion. Secondary outcomes included complete recanalization after the end of the endovascular therapy (including complete recanalization achieved after adjunctive thrombectomy), favorable outcome (90-day modified Rankin Score $\leq 2)$, 90-day all-cause mortality, and any intracerebral hemorrhage. Results: Among the 227 included patients, $18.5 \%(n=42)$ were current smokers and $16.7 \%(n=38)$ former smokers. Compared with nonsmokers, current smokers were younger, more often men, had less frequently hypertension, and cardioembolic etiology, whereas former smokers were more often men and had more frequently hypercholesterolemia. The rate of complete recanalization was $30 \%(n=68)$ after IA rt-PA infusion and 49\% after adjunctive thrombectomy. A higher complete recanali- 
zation rate was found both in current smokers (45.2\%) and former smokers (42.1\%) compared to nonsmokers (22.5\%). After adjustment for potential confounders, the adjusted odds ratio (OR) for complete recanalization associated with ever-smokers was 2.51 [95\% confidence interval (CI) 1.26-4.99; $p=0.009$ ]. A similar adjusted OR was found when the complete recanalization achieved after thrombectomy was included (OR 2.18, 95\% CI 1.13-4.19; $p=0.019$ ). However, smoking status was not independently associated with favorable outcome (adjusted OR 1.41, 95\% CI 0.62-3.22 for former smokers, and adjusted OR 1.35, 95\% CI 0.59-3.05 for current smokers), 90-day all-cause mortality (adjusted OR 0.68, 95\% CI 0.25-1.81 for former smokers, and adjusted OR 1.55, 95\% CI 0.54-4.48 for current smokers) or intracerebral hemorrhage (adjusted OR $0.72,95 \%$ CI $0.29-1.76$ for former smokers, and adjusted OR 0.80, 95\% CI 0.32-1.96 for current smokers). Conclusions: IA rt-PA administration was more effective to achieve complete arterial recanalization in current as well as former smokers. The characterization of the smoking paradox pathophysiology may lead to the identification of a patienttarget population with a favorable response to rt-PA therapy. However, the smoking paradox should not be misinterpreted and not be used to promote smoking. @ 2014 S. Karger AG, Basel

\section{Introduction}

The smoking paradox refers to a better outcome in smokers eligible for thrombolytic treatment. This phenomenon was first described in myocardial infarction (MI) [1] and has been further reported in acute ischemic stroke (AIS) patients treated by intravenous (IV) recombinant tissue plasminogen activator (rt-PA) [2, 3]. A recent study reports that current smokers present higher recanalization rates within $24 \mathrm{~h}$ of symptom onset compared to nonsmokers [2]. Reasons for this association are not fully understood, and conflicting evidences from previous IV rt-PA studies hamper the potential beneficial effect of smoking on favorable outcome after adjustment for confounders [4, 5]. According to this literature, we evaluated if smoking habits impacted recanalization after intra-arterial (IA) rt-PA as well as the prognosis of these patients by examining data from our prospective clinical registry.

\section{Methods}

Patients were identified from a registry of AIS patients treated between April 2007 and December 2012 at the Bichat University Hospital, Paris, France. A detailed description of the materials and methods used has been previously reported [6, 7]. Patients were eligible for inclusion in this study if they had a documented arterial occlusion, were treated with rt-PA administration by IA route ( \pm previous IV rt-PA) and had available information on smoking status. Patients received a combined IV/IA rt-PA dose of $0.9 \mathrm{mg} / \mathrm{kg}$ (IV, $0.6 \mathrm{mg} / \mathrm{kg}$; IA, $0.3 \mathrm{mg}$ / $\mathrm{kg}$ ) in case of documented arterial occlusion and an onset-to-treatment time (OTT) $<4.5 \mathrm{~h}$, or an IA rt-PA dose of $0.5 \mathrm{mg} / \mathrm{kg}$ in case of documented arterial occlusion and an OTT ranging between 4.5 and $6 \mathrm{~h}$. Additional mechanical thrombectomy (MET) was performed if IA rt-PA failed. Informed consent was obtained from the patient or surrogate, and the research protocol was approved by the Ethics Committee from the Ambroise Paré Hospital, Paris, France.

\section{Data Collection and Definitions}

Data were collected using a structured questionnaire. Smoking was classified as current (any smoking within the past 6 months), former ( $>6$ months since cessation) or never smokers. Hypertension and hypercholesterolemia were defined by treatment history. Subjects were 
classified as diabetic when treated for type 1 or type 2 diabetes. The AIS severity was assessed using the NIHSS score at admission. Arterial status of the occluded artery was monitored with conventional angiography during the IA procedure and measured using the Thrombolysis in MI (TIMI) score [8].

All patients underwent a CT or MRI scan $24 \mathrm{~h}$ after treatment onset, to assess hemorrhagic complications. Intracranial hemorrhage was defined and classified according to the ECASS trials $[9,10]$. Functional outcome was assessed at 3 months using the modified Rankin Scale (mRS) during face-to-face interviews or via telephone calls by a senior vascular neurologist (E.M.).

\section{Study Outcome}

The primary study outcome was the percentage of complete recanalization achieved immediately after IA rt-PA infusion, before the use of adjunctive MET if any. Complete recanalization was defined as a complete restoration of blood flow (TIMI 3). Secondary outcome measures included complete recanalization after the end of the endovascular therapy (including complete recanalization achieved after adjunctive MET), favorable outcome (90-day $\mathrm{mRS} \leq 2)$, 90-day all-cause mortality, and intracerebral hemorrhage.

\section{Statistical Analysis}

Patients were categorized into three groups according to the smoking status. Bivariate comparisons of current and former smokers versus nonsmokers (used as control group) were made using $\chi^{2}$ tests for categorical variables (or Fisher's exact test when the expected cell frequency was $<5$ ) and Student's t test for continuous variables (or the Mann-Whitney U test for skewed distribution); a p value $<0.025$ was considered statistically significant (according to the Bonferroni correction). We assessed the smoking status effect on complete recanalization by calculating the odds ratios (ORs). As the ORs for former and current smokers were very similar, we also computed the OR for ever-smokers (current and former smokers combined). Adjustment for age and sex was made using the logistic regression model. The logistic regression model was further adjusted for other significant baseline differences between nonsmokers and smokers (hypercholesterolemia, admission systolic blood pressure, and cardioembolic etiology). We also used the same logistic regression models to evaluate the association of smoking status with secondary outcome measures. Statistical testing was done at the two-tailed $\alpha$ level of 0.05. Data were analyzed with SAS version 9.3 (SAS Institute, Cary, N.C., USA).

\section{Results}

A total of 242 AIS patients with arterial occlusion were treated with IA rt-PA during the study period. Of these, 15 patients with missing information on smoking status were excluded, resulting in a study sample size of 227 patients (fig. 1). One hundred and seventy-four patients were previously treated with IV rt-PA (i.e. using the IV/IA approach), and 69 were treated with adjunctive MET. A total of $18.5 \%(n=42)$ were classified as current smokers and $16.7 \%(n=$ 38) as former smokers. Compared with nonsmokers, current smokers were younger ( $\mathrm{p}$ $0.001)$, more often men ( $p<0.001)$, had less frequently hypertension [history $(p=0.013)$, a lower SBP ( $p<0.001)]$, cardioembolic etiology $(p=0.004)$, whereas former smokers were more often men $(p<0.001)$ and had more frequently hypercholesterolemia $(p<0.001)($ table 1$)$.

\section{Impact of Smoking on Recanalization after IA rt-PA}

Complete recanalization was achieved immediately after IA rt-PA infusion in 30\% ( $\mathrm{n}=$ 68 ) of cases. Both current smokers (45.2\%) and former smokers (42.1\%) had significantly 
Meseguer et al.: The Smoking Paradox: Impact of Smoking on Recanalization in the Setting of Intra-Arterial Thrombolysis

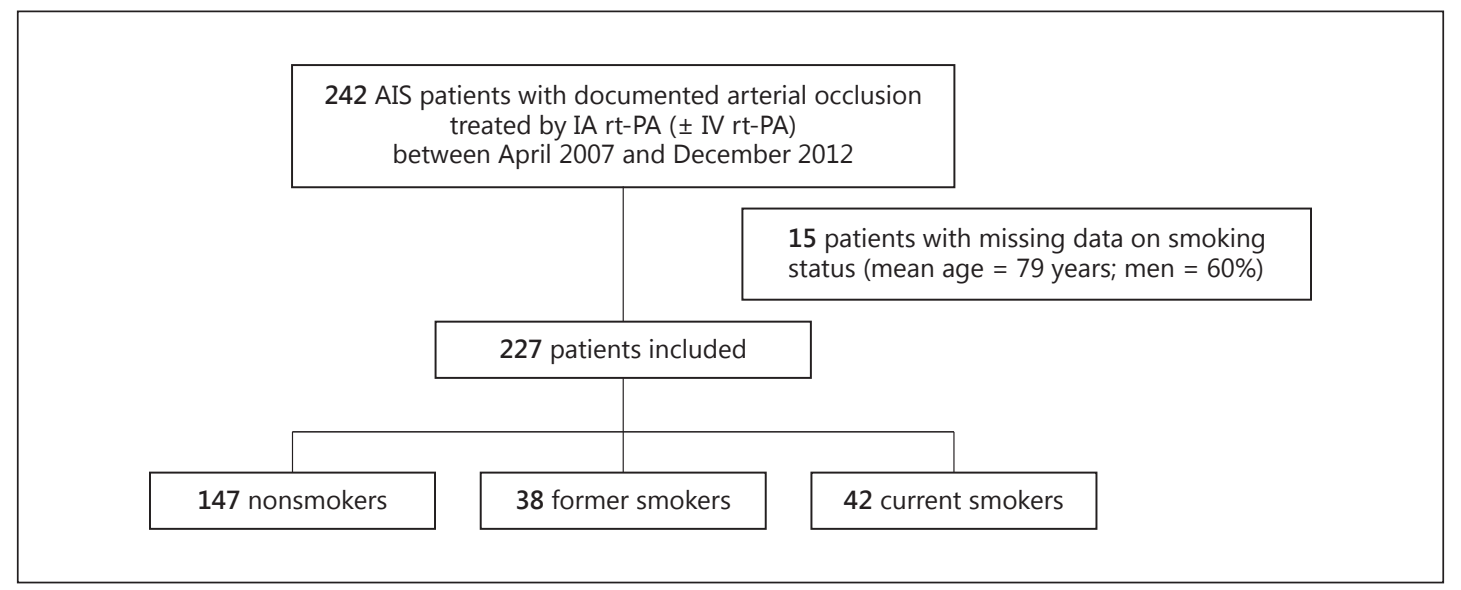

Fig. 1. Flow chart of the study sample.

Table 1. Baseline characteristics according to the smoking status

\begin{tabular}{|c|c|c|c|c|c|}
\hline & $\begin{array}{l}\text { Nonsmokers } \\
(n=147)\end{array}$ & $\begin{array}{l}\text { Former smokers } \\
(n=38)\end{array}$ & $\mathrm{p}^{*}$ & $\begin{array}{l}\text { Current smokers } \\
(\mathrm{n}=42)\end{array}$ & $\mathrm{p}^{*}$ \\
\hline Mean age $\pm S D$, years & $72.5 \pm 17.4$ & $71.7 \pm 13.0$ & 0.75 & $56.4 \pm 13.4$ & $<0.001$ \\
\hline Male gender & $48(32.7)$ & $32(84.2)$ & $<0.001$ & $28(66.7)$ & $<0.001$ \\
\hline \multicolumn{6}{|l|}{ Medical history } \\
\hline Hypertension & $81(55.1)$ & $24(63.2)$ & 0.37 & $14(33.3)$ & 0.013 \\
\hline Diabetes & $15(10.3)$ & $8(21.1)$ & 0.07 & $2(4.8)$ & 0.37 \\
\hline Hypercholesterolemia & $32(21.9)$ & $19(51.4)$ & $<0.001$ & $10(23.8)$ & 0.80 \\
\hline Antithrombotic medications & $51(34.7)$ & $20(52.6)$ & 0.043 & $13(31.0)$ & 0.65 \\
\hline \multicolumn{6}{|l|}{ Clinical and biological markers } \\
\hline Mean platelet count \pm SD $, 1,000 / \mu \mathrm{l}$ & $234 \pm 79$ & $219 \pm 68$ & 0.30 & $239 \pm 70$ & 0.69 \\
\hline Median glucose, mg/dl (IQR) & $119(103-142)$ & $132(104-178)$ & 0.20 & $114(101-140)$ & 0.43 \\
\hline Mean SBP \pm SD, mm Hg & $153 \pm 23$ & $151 \pm 19$ & 0.59 & $139 \pm 20$ & $<0.001$ \\
\hline Mean DBP $\pm \mathrm{SD}, \mathrm{mm} \mathrm{Hg}$ & $82 \pm 13$ & $81 \pm 12$ & 0.70 & $78 \pm 13$ & 0.16 \\
\hline Median NIHSS (IQR) & $18(12-21)$ & $14(8-21)$ & 0.12 & $16(9-22)$ & 0.36 \\
\hline Cardioembolic etiology & $96(65.3)$ & $19(50.0)$ & 0.08 & $17(40.5)$ & 0.004 \\
\hline ICA occlusion (isolated or tandem with MCA) & $35(23.8)$ & $8(21.1)$ & 0.72 & $8(19.1)$ & 0.52 \\
\hline Median OTT, min (IQR) & $150(115-243)$ & $138(110-195)$ & 0.30 & $165(112-245)$ & 0.77 \\
\hline
\end{tabular}

Values are expressed as n (\%) unless otherwise specified. DBP = Diastolic blood pressure; ICA = internal carotid artery; IQR = interquartile range; MCA = middle cerebral artery; NIHSS = National Institutes of Health Stroke Scale; SBP = systolic blood pressure; $\mathrm{SD}=$ standard deviation. * p values for comparisons with nonsmokers.

higher rates of complete recanalization in comparison to nonsmokers (22.5\%). Similar results were found when analysis was restricted to patients treated with combined IV/IA rt-PA (fig. 2). After adjustment for age and sex, current as well as former smokers remained associated with complete recanalization, with an OR of 2.30 [95\% confidence interval (CI) 1.045.10] for current smokers and 2.96 (95\% CI 1.28-6.84) for former smokers. Similar results were found after additional adjustment for hypercholesterolemia, admission systolic blood pressure, and cardioembolic etiology with a nonsignificant OR for current smokers (OR 2.17, 95\% CI 0.96-4.89; $\mathrm{p}=0.061$ ). After combining current and former smokers, the fully adjusted OR for smoking was 2.51 in the main analysis as well as in the sensitivity analysis (fig. 3). 
Meseguer et al.: The Smoking Paradox: Impact of Smoking on Recanalization in the Setting of Intra-Arterial Thrombolysis

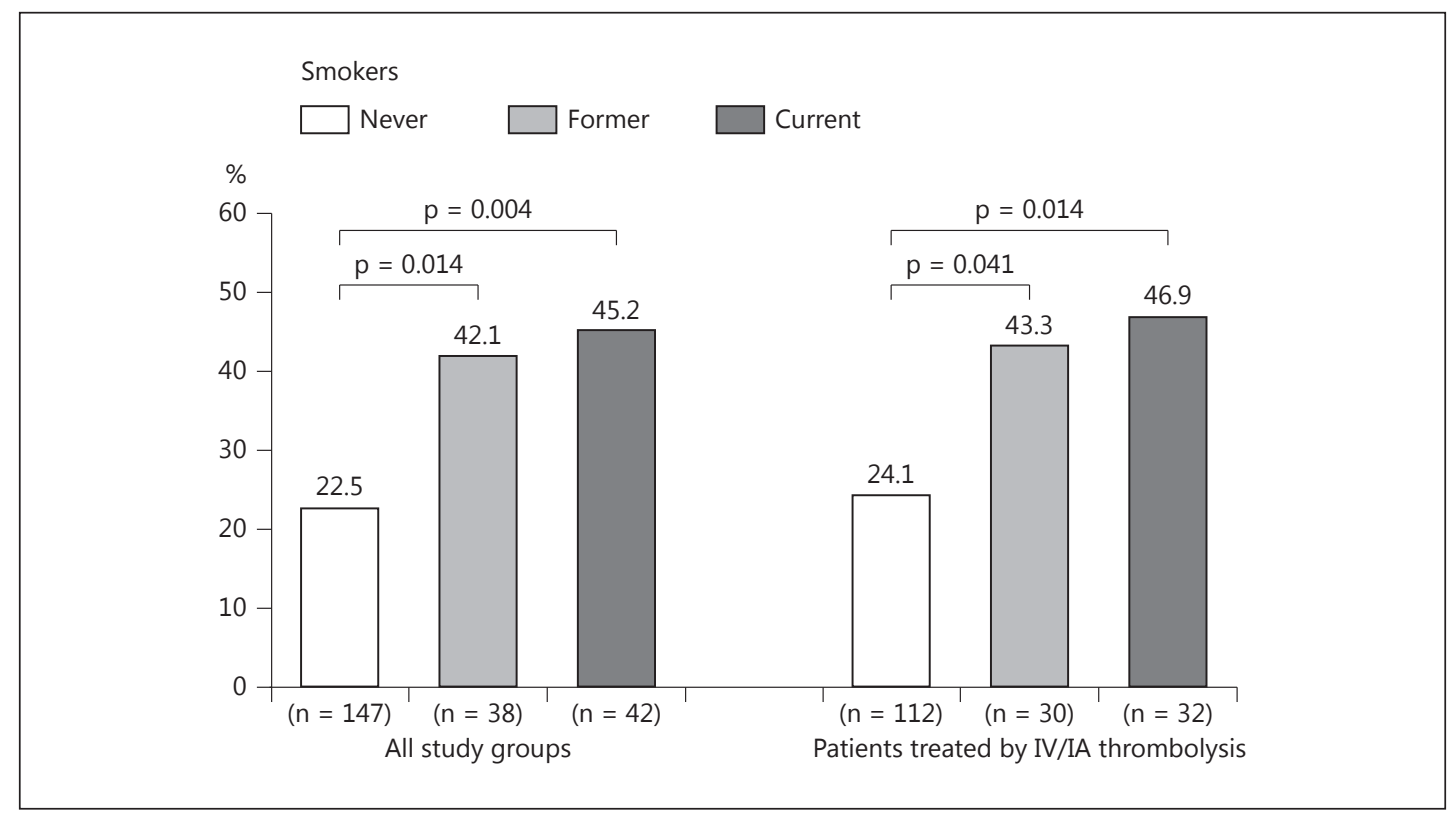

Fig. 2. Rate of complete recanalization after IA rt-PA administration according to smoking status.

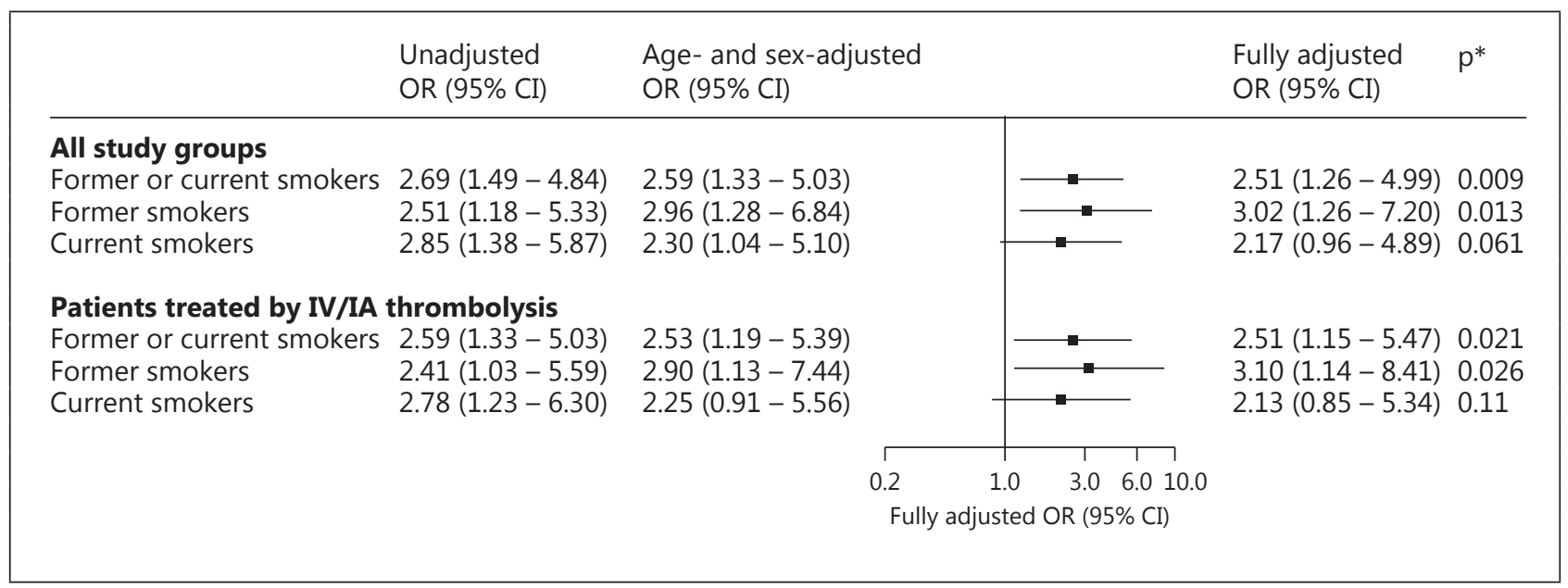

Fig. 3. Unadjusted and adjusted OR for complete recanalization after IA rt-PA administration associated with smoking status. ORs were calculated using nonsmoker as reference group. * Adjusted for age, sex, hypercholesterolemia, admission systolic blood pressure, and cardioembolic etiology.

\section{Impact of Smoking on Secondary Outcomes}

The increased rate of complete recanalization in smokers was also found when complete recanalization after adjunctive MET was considered. As in the main outcome analysis, eversmokers remained significantly associated with higher rate of complete recanalization in the fully adjusted analysis (OR 2.18, 95\% CI 1.13-4.19; $p=0.019$ ), with a nonsignificant OR for current smokers (table 2). Except for a significant higher rate of favorable outcome in current smokers in comparison to nonsmokers ( 63 vs. $45 \%$, p = 0.038), smoking status was not asso- 

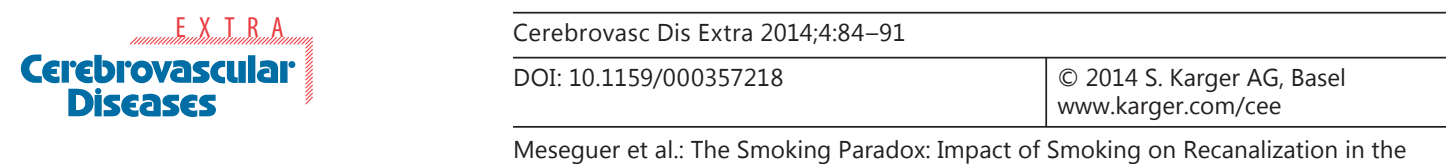

Meseguer et al.: The Smoking Paradox: Impact of Smoking on Recanalization in the Setting of Intra-Arterial Thrombolysis

Table 2. Impact of smoking status on secondary outcomes

\begin{tabular}{|c|c|c|c|c|c|}
\hline & $\begin{array}{l}\text { Nonsmokers } \\
(\mathrm{n}=147)\end{array}$ & $\begin{array}{l}\text { Former smokers } \\
(n=38)\end{array}$ & p* & $\begin{array}{l}\text { Current smokers } \\
(\mathrm{n}=42)\end{array}$ & $\mathrm{p}^{*}$ \\
\hline \multicolumn{6}{|c|}{ Complete recanalization after IA (rt-PA or MET) } \\
\hline Number $(\%)$ & $64(43.5)$ & $22(57.9)$ & & $26(61.9)$ & \\
\hline Unadjusted OR & 1.00 (ref.) & $1.78(0.87-3.67)$ & 0.12 & $2.11(1.04-4.26)$ & 0.038 \\
\hline Age- and sex-adjusted OR & 1.00 (ref.) & $2.08(0.94-4.57)$ & 0.07 & $1.97(0.91-4.26)$ & 0.09 \\
\hline Fully adjusted OR & 1.00 (ref.) & $2.40(1.05-5.50)$ & 0.038 & $2.00(0.90-4.44)$ & 0.09 \\
\hline \multicolumn{6}{|l|}{ Favorable outcome } \\
\hline Number (\%) & $66(44.9)$ & $19(50.0)$ & & $26(63.4)$ & \\
\hline Unadjusted OR & 1.00 (ref.) & $1.23(0.60-2.51)$ & 0.57 & $2.13(1.04-4.34)$ & 0.038 \\
\hline Age- and sex-adjusted OR & 1.00 (ref.) & $1.28(0.58-2.85)$ & 0.54 & $1.31(0.59-2.93)$ & 0.51 \\
\hline Fully adjusted OR & 1.00 (ref.) & $1.41(0.62-3.22)$ & 0.41 & $1.35(0.59-3.05)$ & 0.47 \\
\hline \multicolumn{6}{|l|}{ 90-day mortality } \\
\hline Number (\%) & $40(27.2)$ & $9(23.7)$ & & $8(19.1)$ & \\
\hline Unadjusted OR & 1.00 (ref.) & $0.83(0.36-1.91)$ & 0.66 & $0.63(0.27-1.48)$ & 0.29 \\
\hline Age- and sex-adjusted OR & 1.00 (ref.) & $0.72(0.28-1.88)$ & 0.51 & $1.49(0.52-4.26)$ & 0.46 \\
\hline Fully adjusted OR & 1.00 (ref.) & $0.68(0.25-1.81)$ & 0.44 & $1.55(0.54-4.48)$ & 0.42 \\
\hline \multicolumn{6}{|l|}{ Intracerebral hemorrhage } \\
\hline Number (\%) & $47(32.0)$ & $10(26.3)$ & & $10(23.8)$ & \\
\hline Unadjusted OR & 1.00 (ref.) & $0.76(0.34-1.69)$ & 0.50 & $0.67(0.30-1.47)$ & 0.31 \\
\hline Age- and sex-adjusted OR & 1.00 (ref.) & $0.61(0.25-1.45)$ & 0.26 & $0.73(0.30-1.76)$ & 0.48 \\
\hline Fully adjusted OR* & 1.00 (ref.) & $0.72(0.29-1.76)$ & 0.47 & $0.80(0.32-1.96)$ & 0.62 \\
\hline
\end{tabular}

ciated with any other secondary outcome measures (table 2). In a fully adjusted analysis, current smokers were not associated with an increased rate of favorable outcome (OR 1.35, 95\% CI 0.60-3.05; $\mathrm{p}=0.47$ ).

\section{Discussion}

This study observed an impact of smoking status on recanalization after IA rt-PA administration, showing that smokers have higher recanalization rates compared to nonsmokers. These findings are consistent with previously reported evidences suggesting that current smokers experience higher recanalization rates after IV rt-PA [2]. In addition, we showed that former smokers sustain this beneficial effect on recanalization. These data may be interpreted as a high thrombus responsiveness to rt-PA and probably reflect a different thrombus composition according to smoking habit. Evidences suggest that clots with porous network are more susceptible to fibrinolysis, as well as fibrinogen is an independent predictor of clot permeability [11]. However, smoking has been described to induce faster clot formation and increase fibrin clot resistance to fibrinolysis [12]. These effects are mediated through platelet activation, proinflammatory cytokine and fibrinogen increase $[13,14]$. The contradictory findings on smoking enhanced-fibrinolysis raise the question of the clot abnormalities specificity and its impact on stroke prognosis [15]. If the pathophysiology of the smoking paradox remains unelucidated, it is probably due to the complexity of the involved mechanisms.

The persistence of the observed smoking effect in former smokers is questionable since fibrinogen levels decrease 2 weeks after smoking cessation [13]. Although smoking cessation 
reduces cardiovascular risk [16], the latter decreases by $50 \%$ at 1 year, indicating that this risk is reversible to some extent $[17,18]$. Furthermore, former smokers continue to have an elevated cardiovascular risk even years after they quit smoking [19]. These facts support a long-term effect of smoking on fibrinolysis as observed in the present study.

Even if smokers had a higher rate of recanalization, a favorable outcome was not related to smoking habits in adjusted analyses. The controversial data published according to prognosis $[2-5,20]$ are likely to be related to difference in control of confounders. As previously reported, vascular risk factors are underrepresented in smokers compared to nonsmokers $[2,4,5]$, and more importantly, current smokers are younger than non- or former smokers. Therefore, smokers may be considered as an indicator of baseline characteristics that are associated with better outcome.

The main limitations of our analysis included the use of observational data, and more precisely: the lack of smoking status in $6 \%$ of patients, the absence of data on smoking quantification (e.g. pack-year), and the intrinsic biases in observational studies. However, the smoking prevalence was similar to that reported in a previous large registry of IV and/or IA thrombolysis [21, 22]. We could not exclude that the magnitude of smoking effect on recanalization at $24 \mathrm{~h}$ after IA rt-PA could be different, since recanalization was assessed immediately after termination of the IA rt-PA infusion in our study. However, we found no association with onset to recanalization time, a surrogate marker of thrombolytic efficacy. Finally, we could not exclude a lack of adequate statistical power to detect significant difference in clinical outcome.

In conclusion, the smoking paradox is an interesting concept, which should not be misinterpreted and not be used to promote smoking. The characterization of its pathophysiologic underlying mechanisms may lead to the identification of a patient-target population with a favorable response to rt-PA therapy.

\section{Acknowledgement}

Funding for this study was provided in part by SOS-ATTAQUE CEREBRALE and the Département Hospitalo-Universitaire FIRE (Fibrosis Inflammation Remodeling) of the Université Paris-Diderot, France.

\section{Disclosure Statement}

The authors have no conflicts of interest to disclose.

\section{References}

1 Barbash GI, White HD, Modan M, Diaz R, Hampton JR, Heikkila J, Kristinsson A, Moulopoulos S, Paolasso EA, Van der Werf T: Significance of smoking in patients receiving thrombolytic therapy for acute myocardial infarction. Experience gleaned from the International Tissue Plasminogen Activator/Streptokinase Mortality Trial. Circulation 1993;87:53-58.

2 Kufner A, Nolte CH, Galinovic I, Brunecker P, Kufner GM, Endres M, Fiebach JB, Ebinger M: Smoking-thrombolysis paradox: recanalization and reperfusion rates after intravenous tissue plasminogen activator in smokers with ischemic stroke. Stroke 2013;44:407-413.

-3 Plas GJ, Uyttenboogaart M, Luijckx GJ: 'Smoking-thrombolysis paradox: recanalization and reperfusion rates after intravenous tissue plasminogen activator in smokers with ischemic stroke'. Stroke 2013;44:e58.

-4 Moulin S, Padjen-Bogosavljevic V, Marichal A, Cordonnier C, Jovanovic DR, Gautier S, Hénon H, Beslac-Bumbasirevic L, Bordet R, Leys D: Influence of differences in case mix on the better outcome of smokers after intravenous thrombolysis for acute cerebral ischemia. Eur Neurol 2012;67:178-183. 
Meseguer et al.: The Smoking Paradox: Impact of Smoking on Recanalization in the Setting of Intra-Arterial Thrombolysis

5 Aries MJ, Uyttenboogaart M, Koch MW, Langedijk M, Vroomen PC, Luijckx GJ, De Keyser J: Does smoking influence outcome after intravenous thrombolysis for acute ischaemic stroke? Eur Neurol 2009;16:819-822.

6 Meseguer E, Mazighi M, Lapergue B, Labreuche J, Sirimarco G, Gonzalez-Valcarcel J, Lavallée PC, Cabrejo L, Guidoux C, Klein IF, Olivot JM, Rouchaud A, Desilles JP, Amarenco P: Outcomes after thrombolysis in AIS according to prior statin use: a registry and review. Neurology 2012;79:1817-1823.

7 Mazighi M, Labreuche J, Meseguer E, Serfaty JM, Laissy JP, Lavallée PC, Cabrejo L, Guidoux C, Lapergue B, Klein IF, Olivot JM, Abboud H, Simon O, Schouman-Claeys E, Amarenco P: Impact of a combined intravenous/intraarterial approach in octogenarians. Cerebrovasc Dis 2011;31:559-565.

-8 The Thrombolysis in Myocardial Infarction (TIMI) trial. Phase I findings. TIMI Study Group. N Engl J Med 1985; 312:932-936.

-9 Hacke W, Kaste M, Fieschi C, Toni D, Lesaffre L, von Kummer R, Boysen G, Bluhmki E, Höxter G, Mahagne MH, Hennerici M: Intravenous thrombolysis with recombinant tissue plasminogen activator for acute hemispheric stroke. The European Cooperative Acute Stroke Study (ECASS). JAMA 1995;274:1017-1025.

-10 Hacke W, Kaste M, Fieschi C, von Kummer R, Davalos A, Meier D, Larrue V, Bluhmki E, Davis S, Donnan G, Schneider D, Diez-Tejedor E, Trouillas P: Randomised double-blind placebo-controlled trial of thrombolytic therapy with intravenous alteplase in acute ischaemic stroke (ECASS II). Second European - Australasian Acute Stroke Study Investigators. Lancet 1998;352:1245-1251.

11 Barua RS, Sy F, Srikanth S, Huang G, Javed U, Buhari C, Margosan D, Ambrose JA: Effects of cigarette smoke exposure on clot dynamics and fibrin structure: an ex vivo investigation. Arterioscler Thromb Vasc Biol 2010; 30:75-79.

12 Undas A, Topór-Madry R, Tracz W, Pasowicz M: Effect of cigarette smoking on plasma fibrin clot permeability and susceptibility to lysis. Thromb Haemost 2009;102:1289-1291.

13 Hunter KA, Garlick PJ, Broom I, Anderson SE, McNurlan MA: Effects of smoking and abstention from smoking on fibrinogen synthesis in humans. Clin Sci (Lond) 2001;100:459-465.

14 Wolberg AS: Plasma and cellular contributions to fibrin network formation, structure and stability. Haemophilia 2010;16(suppl 3):7-12.

15 Undas A, Slowik A, Wolkow P, Szczudlik A, Tracz W: Fibrin clot properties in acute ischemic stroke: relation to neurological deficit. Thrombosis Research 2010;125:357-361.

16 Dobson AJ, Alexander HM, Heller RF, Lloyd DM: How soon after quitting smoking does risk of heart attack decline? J Clin Epidemiol 1991;44:1247-1253.

-17 Goldenberg I, Jonas M, Tenenbaum A, Boyko V, Matetzky S, Shotan A, Behar S, Reicher-Reiss H; Bezafibrate Infarction Prevention Study Group: Current smoking, smoking cessation, and the risk of sudden cardiac death in patients with coronary artery disease. Arch Int Med 2003;163:2301-2305.

-18 Grundy SM, Balady GJ, Criqui MH, Fletcher G, Greenland P, Hiratzka LF, Houston-Miller N, Kris-Etherton P, Krumholz HM, LaRosa J, Ockene IS, Pearson TA, Reed J, Washington R, Smith SC Jr: Primary prevention of coronary heart disease: guidance from Framingham: a statement for healthcare professionals from the AHA Task Force on Risk Reduction. American Heart Association. Circulation 1998;97:1876-1887.

19 Jöckel KH, Lehmann N, Jaeger BR, Moebus S, Möhlenkamp S, Schmermund A, Dragano N, Stang A, Grönemeyer D, Seibel R, Mann K, Volbracht L, Siegrist J, Erbel R: Smoking cessation and subclinical atherosclerosis - results from the Heinz Nixdorf Recall Study. Atherosclerosis 2009;203:221-227.

20 Ovbiagele B, Saver JL: The smoking-thrombolysis paradox and acute ischemic stroke. Neurology 2005;65: 293-295.

21 Galimanis A, Jung S, Mono ML, Fischer U, Findling O, Weck A, Meier N, De Marchis GM, Brekenfeld C, El-Koussy M, Mattle HP, Arnold M, Schroth G, Gralla J: Endovascular therapy of 623 patients with anterior circulation stroke. Stroke 2012;43:1052-1057.

22 Wahlgren N, Ahmed N, Eriksson N, Aichner F, Bluhmki E, Dávalos A, Erilä T, Ford GA, Grond M, Hacke W, Hennerici MG, Kaste M, Köhrmann M, Larrue V, Lees KR, Machnig T, Roine RO, Toni D, Vanhooren G; Safe Implementation of Thrombolysis in Stroke-MOnitoring STudy Investigators: Multivariable analysis of outcome predictors and adjustment of main outcome results to baseline data profile in randomized controlled trials: Safe Implementation of Thrombolysis in Stroke-MOnitoring STudy (SITS-MOST). Stroke 2008;39:3316-3322. 